\title{
Defensive Medicine and Tort Reform: A Wide View
}

\author{
David M. Studdert, LLB, SCD, MPH' , Michelle M. Mello, JD, PhD, M.Phil', \\ and Troyen A. Brennan, MD, JD, MPH ${ }^{3}$
}

${ }^{1}$ School of Law and School of Population Health, University of Melbourne, Melbourne, Australia; ${ }^{2}$ Department of Health Policy and Management, Harvard School of Public Health, Boston, USA; ${ }^{3}$ CVS/Caremark, Woonsocket, RI, USA.

J Gen Intern Med 25(5):380-1

DOI: $10.1007 / \mathrm{s} 11606-010-1319-8$

(c) Society of General Internal Medicine 2010

$\mathrm{H}$ ermer and Brody's ${ }^{1}$ analysis of the relationship between defensive medicine and tort reform in this issue of the Journal of General Internal Medicine deftly tackles a number of the major issues in this vexatious policy area. The authors' main conclusion is that tort reform is a necessary but not sufficient measure to bend the health care cost curve. Although defensive medicine costs are small as a proportion of aggregate national health expenditures, without reforms to address the liability fear that drives defensive practices, it will be difficult to move physicians toward cost-effective health care delivery. We agree. In this editorial, we offer some further thoughts on the points raised by Hermer and Brody.

The first point is that, despite what the loudest voices in the malpractice debate might suggest, rigorous measurement of the prevalence and costs of defensive medicine is elusive. Bold claims about defensive medicine often focus its impact on health system costs. But the challenge begins, as Hermer and Brody note, with the concept of defensive medicine itself, which is very slippery.

Consider the computed tomography scan done in an emergency department. Is the doctor who orders it motivated by a desire to avoid litigation, by cautiousness unrelated to medico-legal fears, or by the culture of the clinical environment in which she works (which itself, may be shaped to varying degrees by legal risk management concerns)? Or perhaps the motivation is financial: has the hospital spotted a revenue stream from giving patients easy access to its new high-speed scanner? Even when the treatment decision can be pinned to the specter of litigation, in whole or part, what if the scan's appropriateness in the clinical circumstances at hand sits in a grey area, neither clearly needed nor contraindicated? What if it was ordered for all the wrong reasons, yet turns out to reveal something clinically significant, benefiting the patient?

Studies of clinical behavior at the system or population level cannot disentangle motivations, and rarely can account for the clinical benefit of "defensive" practices. Survey research can probe personal motivations, but has different limitations. Because many physicians are attuned to defensive medicine as a problem, and their professional organizations agitate prominently against it, self-report data will always be prone

Published online March 27, 2010 to a "socially-desirable response bias". In sum, the conceptual complexity of defensive medicine means that the even the most rigorous health services research will struggle to isolate its role as an independent driver of clinical decision making and its effects on the quantity and quality of services delivered. Consequently, it is difficult to draw strong conclusions about how much savings will result if defensive medical practice is reduced.

A second point is that evaluating malpractice reform by reference to how well it controls costs through reducing the impulse toward defensive practice in some ways misses the point. Tort law, of which medical malpractice is one branch, is supposed to compensate patients for the losses they experience due to negligent injury and deter negligence in the future ${ }^{2}$. Tort scholars conceive of defensive medicine as "overdeterrence," meaning that signals from tort law lead physicians to take more precautions than are socially optimal (considering both the injury-reducing potential of the precautions and their cost) ${ }^{3}$. Tort reforms should be evaluated not only for their potential to avoid overdeterrence, but also for their potential to achieve appropriate, "true" deterrence- that is, to reduce the incidence of injury due to substandard care. Evaluations should also take into account reforms' potential to ensure that the liability system reliably delivers compensation to patients who sustain an injury due to negligence.

The medical liability system is replete with fundamental problems of misalignment that go far beyond defensive medicine. The most serious is the well-documented mismatch between negligent injuries and malpractice litigation ${ }^{4-6}$. Most instances of negligence do not result in malpractice claims, many malpractice claims do not involve negligent injuries, and the outcomes of malpractice claims often do not match the merits of the claim. Although this mismatch itself drives defensive medicine, because physicians cannot feel secure that practicing reasonable care will protect them from being sued, the point is consistently lost in discussions of the need to curb defensive medicine. Liability reform should focus on ways to enhance the system's ability to achieve its core objectives: spurring improvements in quality and safety and compensating injured patients. Even if the goal of liability reform is more limited, to simply reducing defensive medicine, it is still imperative to address the mismatch problem.

This leads to a third point: conventional tort reforms like caps on noneconomic damages seek merely to limit the economic cost of malpractice litigation for providers, not to change fundamental aspects of how the liability system works. Thus, we might say, they treat the symptoms, not the disease. The question raised by the Hermer and Brody piece, then, is not, is liability reform needed, but what kind of liability reform?

The factors Hermer and Brody cite as key reasons to adopt tort reforms are not things that conventional reforms address. 
The mismatch problem, high overhead costs, and the focus on individual culpability rather than systems breakdowns are all untouched (or even exacerbated) by traditional reforms. For example, limiting the amount of damages for which nonprofit hospitals can be held liable, as some states do, can lead plaintiffs to target individual physicians. Pretrial screening panels add a layer of administrative costs to the litigation process, leading to higher litigation costs overall.

Conventional tort reforms also may not achieve the kind of quid pro quo that Hermer and Brody contemplate. They hope that tort reform will make physicians more likely to practice cost-effective care and to acquiesce to policy and practice changes that lower their reimbursement. Although damages caps have been shown to be associated with lower health care utilization in some contexts, as Hermer and Brody discuss, they address only one dimension of the fear that leads physicians to practice defensively. They limit the economic consequences of being sued, but do not necessarily reduce the risk of suit itself, nor any of the unpleasant aspects of the adversarial litigation process.

More promising in achieving the objectives Hermer and Brody outline are more innovative reforms that alter providers' and liability insurers' responses to medical injury and provide legal protection for adhering to evidence-based practice ${ }^{7}$. Creating legal "safe harbors" for physicians who adhere to credible clinical guidelines, for example, could well inspire greater adherence to cost-effective care. Reforms-whether instituted by law or voluntarily implemented by provider organizations and insurers-that facilitate early offers of compensation to injured patients may prevent litigation, reduce litigation costs, and result in lower total liability expenditures. Eliminating fights about negligence by removing this as a condition for receiving compensation could substantially reduce the most painful and stigmatizing aspects of medical injury compensation for physicians. Offering compensation for all avoidable injuries, whether due to negligence or not, would also further the systemic objectives of redressing injuries and providing incentives for safety improvement.

That brings us a fourth and final point. Today, ten years after the Institute of Medicine's launch of the safety movement, patient safety fails to carry the day in many policy debates about liability and health care reform. The linkage of safety to professionalism motivates ongoing research and some real breakthroughs, ${ }^{8,9}$ but it is still difficult to identify a convincing business case for improved safety. Some changes are evident: institutions embarrassed by tragic cases must react, many new patient safety programs have been launched, and hospital risk managers really have acquired safety expertise. But it seems unlikely that substantial reductions in the incidence of medical injuries have occurred, ${ }^{10}$ and whether appropriate levels of resources have been invested in efforts to improve patient safety is questionable.

How could that change? We believe nontraditional medical liability reforms can be part of the solution. But as Hermer and Brody quite rightly point out, this is only the beginning. If a true circuit breaker exists, it is likely to be found outside the medical malpractice system itself. One possibility is to alter reimbursement mechanisms to force providers to bear greater financial responsibility for medical injuries or provide greater "pay-for-performance" rewards for reducing injuries. There are already moves among major payers to restrict reimbursement for "never events," but farther-reaching payment reform may be needed. Whether liability reform will be a sufficient sweetener to win providers' support for such changes-either in this round of health reform or in the next-remains to be seen.

Corresponding Author: Troyen A. Brennan, MD, JD, MPH; CVS/ Caremark, 1 CVS Drive, Woonsocket, RI 02895, USA (email: tabrennan@cus.com).

\section{REFERENCES}

1. Hermer LD, Brody H. Defensive medicine, cost containment, and reform. J Gen Intern Med. 2010. doi:10.1007/s11606-010-1259-3.

2. Studdert DM, Mello MM, Brennan TA. Medical malpractice. N Engl J Med. 2004;350:283-92.

3. Mello MM, Brennan TA. Deterrence of medical errors: theory and evidence for malpractice reform. Texas Law Rev. 2002;80:1595-637.

4. Localio AR, Lawthers AG, Brennan TA, et al. Relation between malpractice claims and adverse events due to negligence: results of the Harvard Medical Practice Study III. N Engl J Med. 1991;325:245-51.

5. Studdert DM, Thomas EJ, Burstin HR, Zbar BI, Orav EJ, Brennan TA. Negligent care and malpractice claiming behavior in Utah and Colorado. Med Care. 2000;38(3):250-60.

6. Studdert DM, Mello MM, Gawande AA, etal. Claims, errors, and compensation payments in medical malpractice litigation. N Engl J Med. 2006;354:2024-33.

7. Mello MM, Brennan TA. The role of medical liability reform in federal health reform. N Engl J Med. 2009;361(1):1-3.

8. Pronovost $\mathbf{P}$, Needham $\mathbf{D}$, Berenholtz $\mathbf{S}$, et al. An intervention to decrease catheter-related bloodstream infections in the ICU. N Engl J Med. 2006;355:2725-32.

9. Haynes AB, Weiser TG, Berry WR, et al. A surgical safety checklist to reduce morbidity and mortality in a global population. $\mathrm{N}$ Engl $\mathrm{J}$ Med. 2009;360:491-9.

10. Leape LL, Berwick DM. Five years after "To Err Is Human"-What have we learned? JAMA. 2005;293:2384-90 